\title{
Toxicity of essential oil from Indian borage on the larvae of the African malaria vector mosquito, Anopheles gambiae
}

\author{
Eliningaya J Kweka ${ }^{1 *}$, Annadurai Senthilkumar ${ }^{2}$ and Venugopalan Venkatesalu ${ }^{2}$
}

\begin{abstract}
Background: Essential oils are currently studied for the control of different disease vectors, because of their efficacy on targeted organisms. In the present investigation, the larvicidal potential of essential oil extracted from Indian borage (Plectranthus amboinicus) was studied against the African anthropophagic malaria vector mosquito, Anopheles gambiae. The larvae of An. gambiae s.s laboratory colony and An. gambiae s.l of wild populations were assayed and the larval mortality was observed at 12, 24 and $48 \mathrm{~h}$ after exposure period with the concentrations of $3.125,6.25,12.5,25,50$ and 100 ppm.

Findings: Larval mortality rates of the essential oil was entirely time and dose dependent. The $L C_{50}$ values of the laboratory colony were 98.56 (after 12h) 55.20 (after $24 \mathrm{~h}$ ) and $32.41 \mathrm{ppm}$ (after $48 \mathrm{~h}$ ) and the LC 90 values were 147.40 (after 12h), 99.09 (after $24 \mathrm{~h}$ ) and $98.84 \mathrm{ppm}$ (after $48 \mathrm{~h}$ ). The $\mathrm{LC}_{50}$ and $L \mathrm{C}_{90}$ values of the wild population were 119.52, 179.85 (after 12h) 67.53, 107.60 (after 24 h) and 25.51, 111.17 ppm (after $48 \mathrm{~h}$ ) respectively. The oil showed good larvicidal potential after $48 \mathrm{~h}$ of exposure period against An. gambiae. The essential oil of Indian borage is a renowned natural source of larvicides for the control of the African malaria vector mosquito, An. gambiae.
\end{abstract}

Conclusion: The larvicidal efficacy shown by plant extracts against An. gambiae should be tested in semi field and small scale trials for effective compounds to supplement the existing larval control tools.

\section{Findings}

\section{Background}

Malaria is the most important parasitic disease that has created major public health problems in the tropical and sub-tropical regions, in spite of the decrease of malaria cases and vector populations. According to a global estimate from The World Health Organization (WHO), 216 million people who were infected with malaria parasites in 2010, (of which approximately $81 \%$, or 174 million cases, were reported from Sub-Saharan African) resulted in 6, 55, 000 malaria deaths (about 91\% were in Africa) [1]. Approximately $86 \%$ of malaria deaths globally were children under 5 years of age. Mosquitoes of the Anopheles gambiae Giles complex are the principal and most efficient malaria vectors in the world [2].

\footnotetext{
* Correspondence: pat.kweka@gmail.com

'Division of Livestock and Human Diseases Vector Control, Tropical Pesticides Research Institute, Ngaramtoni, Off Nairobi Road, P.O. Box 3024, Arusha, Tanzania

Full list of author information is available at the end of the article
}

Among the An. gambiae complex members, An. gambiae s.s. plays a wide role in transmission of the most dangerous parasite, Plasmodium falciparum in Sub-Saharan countries [2].

The use of synthetic insecticides for the control of adult anopheline mosquitoes through indoor residual house spraying and insecticide impregnated materials have shown to decrease in efficacy over time in recent years in various parts of Africa [3]. This is due to the tolerance of adult mosquitoes against synthetic insecticides used for bed nets/indoor residual spray [1] and the widespread use of a single class of insecticide increases the risk that mosquitoes will develop resistance, which could rapidly lead to a major public health problem [4]. Targeting the mosquito larval stage by using non synthetic or alternative larvicides can be of significant impact as larvae cannot move from breeding sites [5]. In recent years, searching for new mosquito control agents from natural sources such as essential oil has gained recognition among researchers in countries with a renowned 
biodiversity and large numbers of plants/essential oils have been reported to possess larvicidal and repellent activity [6-8].

Indian borage [Plectranthus amboinicus (Lour.) Spreng] belongs to the family Lamiaceae and it grows naturally and is distributed in tropical Africa and Asia. In the previous studies of the essential oil of $P$. amboinicus for its chemical composition and larvicidal activity against An. stephensi [9], the oil showed marked larvicidal potential with the $\mathrm{LC}_{50}$ values of the oil being 33.54 (after $12 \mathrm{~h}$ ) and $28.37 \mathrm{ppm}$ (after $24 \mathrm{~h}$ ) against An. stephensi [9]. Based on the previous report, the current study evaluated the toxicity of this essential oil against the laboratory colony (An. gambiae s.s) and wild populations of the African malaria vector mosquito, An. gambiae s.l.

\section{Methods}

\section{Plant materials and extraction of essential oil}

The fresh leaves of Indian borage were collected from Mangudi $\left(11^{\circ} 20^{\prime} 35 \mathrm{~N}, 079^{\circ} 41^{\prime} 24 \mathrm{E}\right)$, Cuddalore district of Tamil Nadu, India during April, 2010. The leaves were cut into small pieces and subjected to hydro distillation using a Clevenger type apparatus for $4 \mathrm{~h}$. The essential oil was dried over anhydrous sodium sulphate and the purified essential oil was stored at $+4^{\circ} \mathrm{C}$ for further use. The specimen voucher was deposited at the herbarium, Department of Botany, Annamalai University. The specimen voucher number is AUBOT\#231.

\section{Larval collection and rearing of mosquitoes}

An. gambiae s.s. laboratory colony was reared in an insectary and maintained at $27.0 \pm 2^{\circ} \mathrm{C}$ and relative humidity of 70 to $80 \%$. The light regime was L 12: D 12 . These females were provided with sugar solution $(10 \%$ sucrose). Species identification of the An. gambiae s.s. was performed and confirmed by using polymerase chain reaction as described by the protocol of Scott et al. [10]. Eggs laid were collected on wet filter papers and kept in an incubator for 48 hours before hatching. Larvae were fed with diet of Brewer's yeast until they developed to third instar larvae. Wild populations of larvae were sampled from natural habitats using a standard dipper of $350 \mathrm{ml}$ in areas with a history of pyrethroid resistance observed in adult populations in western Kenya. Sampled larvae were sorted in an insectary and only third instar larvae of An. gambiae were used for larvicidal activity.

\section{Mosquito larvicidal assay}

The larvicidal activity was analysed as per the standard procedures recommended by the World Health Organisation [11]. The essential oil was dissolved in $1 \mathrm{ml}$ of acetone and prepared in different concentrations viz.,
$3.125,6.25,12.5,25,50$ and $100 \mathrm{ppm}$ with distilled water. Twenty larvae (in a $20 \mathrm{ml}$ beaker) of late third instar stage were used for larvicidal assay and five replicates were maintained for each concentration. Larval mortality was counted after 12,24 and 48 h exposure and during the experimental period no food was offered to the larvae. All moribund mosquito larvae were considered as dead. The larval mortality was also checked for water and acetone individually. The lethal concentrations, $\mathrm{LC}_{50}$ and $\mathrm{LC}_{90}$ and their $95 \%$ confidence limit of upper and lower confidence levels were calculated by probit analysis in a Statistical package for social scientists, version 11.5 (SPSS Inc., Chicago, IL).

\section{GC and GC-MS analysis}

Gas chromatography (GC) analysis was carried out using Varian 3800 gas chromatography equipped with mass

Table 1 Chemical composition of the essential oil from the leaves of $P$. amboinicus [9]

\begin{tabular}{|c|c|c|c|}
\hline Peak No & Al & Chemical compound & Percentage \\
\hline 1 & 788 & 1-octene & 0.35 \\
\hline 2 & 988 & myrcene & 0.16 \\
\hline 3 & 1014 & a-terpinene & 0.61 \\
\hline 4 & 1020 & $\rho$-cymene & 6.51 \\
\hline 5 & 1025 & $\beta$-phelandrene & 0.11 \\
\hline 6 & 1054 & $\gamma$ - terpinene & 7.76 \\
\hline 7 & 1098 & trans-sabinene hydrate & 0.22 \\
\hline 8 & 1123 & methyl octanoate & 0.42 \\
\hline 9 & 1165 & borneol & 0.26 \\
\hline 10 & 1186 & a-terpineol & 3.28 \\
\hline 11 & 1192 & dihydro carvel & 0.23 \\
\hline 12 & 1195 & methyl chavicol & 0.28 \\
\hline 13 & 1197 & 2Z-octenol acetate & 0.96 \\
\hline 14 & 1289 & thymol & 21.66 \\
\hline 15 & 1298 & carvacrol & 29.25 \\
\hline 16 & 1305 & undecanal & 8.29 \\
\hline 17 & 1452 & a-humulene & 9.67 \\
\hline 18 & 1489 & $\beta$-selinene & 2.01 \\
\hline 19 & 1582 & caryphyllene oxide & 5.83 \\
\hline 20 & 1584 & 2-phenyl ethyl tiglate & 1.38 \\
\hline 21 & 1590 & $\beta$ - copaen-4-a-ol & 0.12 \\
\hline 22 & 1608 & humulene epoxide II & 0.11 \\
\hline 23 & 1611 & tetradecanal & 0.12 \\
\hline 24 & 1615 & $\beta$-himachalene oxide & 0.15 \\
\hline 25 & 1621 & $\beta$-cedrene epoxide & 0.03 \\
\hline \multirow[t]{2}{*}{26} & 1627 & 1-epi-cubenol & 0.16 \\
\hline & & TOTAL & 99.93 \\
\hline
\end{tabular}

Al (Arithmetic Index) in the literature [12]. 
selective detector coupled to front injector type 1079 . The chromatograph was fitted with DB 5 MS capillary column (30 $\mathrm{m} \times 0.25 \mathrm{~mm}$ i.d., film thickness $0.25 \mu \mathrm{m}$ ). The injector temperature was set at $280^{\circ} \mathrm{C}$, and the oven temperature was initially at $45^{\circ} \mathrm{C}$ then programmed to $300^{\circ} \mathrm{C}$ at the rate of $10^{\circ} \mathrm{C} / \mathrm{min}$ and finally held at $200^{\circ} \mathrm{C}$ for $5 \mathrm{~min}$. Helium was used as a carrier gas with the flow rate of $1.0 \mathrm{ml} / \mathrm{min}$. One microlitre of the sample (diluted with acetone 1:10) was injected in the split mode in the ratio of 1:100. The percentage of

Table 2 Larvicidal activity of essential oil from Indian borage against a laboratory colony and wild population of African malarial vector mosquitoes, Anopheles gambiae s.s. after 12 and 24 hours 12, 24 and $48 \mathrm{~h}$ of exposure period respectively

\begin{tabular}{|c|c|c|c|c|c|c|}
\hline & Concentration (ppm) & Time & Mortality & $\mathrm{LC}_{50}(\mathrm{LCL}-\mathrm{UCL})^{\mathrm{a}}$ & $\mathrm{LC}_{90}(\mathrm{LCL}-\mathrm{UCL})^{\mathrm{a}}$ & $X^{2}(\mathrm{df}=4)^{b}$ \\
\hline \multirow{18}{*}{$\begin{array}{c}\text { Laboratory colony } \\
\text { (An. gambiae s.s) }\end{array}$} & 3.125 & After 12 Hours & $0 \pm 0.0$ & $98.56(76.55-158.18)$ & $147.40(112.35-276.75)$ & 25.52 \\
\hline & 6.25 & & $0 \pm 0.0$ & & & \\
\hline & 12.5 & & $0 \pm 0.0$ & & & \\
\hline & 25 & & $0 \pm 0.0$ & & & \\
\hline & 50 & & $26 \pm 1.30$ & & & \\
\hline & 100 & & $55 \pm 1.58$ & & & \\
\hline & 3.125 & After 24 Hours & $3 \pm 0.89$ & $55.20(35.26-96.69)$ & $99.09(70.65-203.33)$ & 49.36 \\
\hline & 6.25 & & $5 \pm 0.70$ & & & \\
\hline & 12.5 & & $14 \pm 0.83$ & & & \\
\hline & 25 & & $16 \pm 1.48$ & & & \\
\hline & 50 & & $83 \pm 1.67$ & & & \\
\hline & 100 & & $98 \pm 0.54$ & & & \\
\hline & 3.125 & After 48 Hours & $23 \pm 1.14$ & $32.41(8.23-62.40)$ & $98.84(66.67-242.69)$ & 30.57 \\
\hline & 6.25 & & $29 \pm 0.70$ & & & \\
\hline & 12.5 & & $51 \pm 0.83$ & & & \\
\hline & 25 & & $55 \pm 1.0$ & & & \\
\hline & 50 & & $95 \pm 0.70$ & & & \\
\hline & 100 & & $100 \pm 0.0$ & & & \\
\hline \multirow[t]{18}{*}{ Wild population (An. gambiae s.l) } & 3.125 & After 12 Hours & $0 \pm 0.0$ & 119.52 (98.53 - 164.94) & $179.85(143.12-268.45)$ & 8.19 \\
\hline & 6.25 & & $0 \pm 0.0$ & & & \\
\hline & 12.5 & & $1 \pm 0.44$ & & & \\
\hline & 25 & & $2 \pm 0.89$ & & & \\
\hline & 50 & & $15 \pm 1.58$ & & & \\
\hline & 100 & & $37 \pm 1.14$ & & & \\
\hline & 3.125 & After 24 Hours & $0 \pm 0.0$ & $67.53(55.31-85.22)$ & $107.60(88.92-143.21)$ & 16.23 \\
\hline & 6.25 & & $0 \pm 0.0$ & & & \\
\hline & 12.5 & & $3 \pm 0.89$ & & & \\
\hline & 25 & & $14 \pm 0.83$ & & & \\
\hline & 50 & & $47 \pm 1.14$ & & & \\
\hline & 100 & & $96 \pm 0.83$ & & & \\
\hline & 3.125 & After 48 Hours & $42 \pm 1.67$ & $25.51(0.25-46.94)$ & $111.17(76.91-238.56)$ & 16.63 \\
\hline & 6.25 & & $44 \pm 2.68$ & & & \\
\hline & 12.5 & & $52 \pm 1.51$ & & & \\
\hline & 25 & & $52 \pm 2.07$ & & & \\
\hline & 50 & & $95 \pm 0.70$ & & & \\
\hline & 100 & & $98 \pm 0.54$ & & & \\
\hline
\end{tabular}

a - 95\% Confidence interval.

b - Degrees of freedom.

LCL Lower Confidence level, UCL Upper Confidence level. 
composition of the essential oil was calculated by the GC peak areas. GC-mass spectrometry (GC-MS) analysis of essential oil was performed using Varian 3800 gas chromatography equipped with Varian 1200L single quadrupole mass spectrometer. GC conditions were the same as reported for GC analysis and the same column was used. The mass spectrometer was operated in the electron impact mode at $70 \mathrm{eV}$. Ion source and transfer line temperature was kept at $250^{\circ} \mathrm{C}$. The mass spectra were obtained by centroid scan of the mass range from 40 to $1,000 \mathrm{amu}$. The retention indices were calculated using a homologous series of n-alkanes, $\mathrm{C}_{8}-\mathrm{C}_{22}$ and n-octane was used as the internal standard. The compounds were identified based on the comparison of their retention indices (RI), retention time (RT) and mass spectra of WILEY, NIST library data of the GC-MS system and literature data [12].

\section{Results and discussion}

The analysis of the chemical contents of the samples of essential oil from $P$. amboinicus revealed that the essential oil had 26 compounds (Table 1). The essential oil of Indian borage showed good larvicidal toxicity (Table 2) against both An. gambiae larvae of a laboratory colony and wild populations. The laboratory colony showed 100 per cent larval mortality at 100 ppm after $48 \mathrm{~h}$ of exposure period. The $\mathrm{LC}_{50}$ values of essential oil against the larvae of the laboratory colony was 98.56, 55.20 and $32.41 \mathrm{ppm}$ and $\mathrm{LC}_{90}$ values were 14.40, 99.09 and 98.84 ppm after 12, 24 and $48 \mathrm{~h}$ of exposure period respectively. The larvae of the wild population showed poor response for the essential oil after $12 \mathrm{~h}$ of exposure period. Even though, the essential oil showed low $\mathrm{LC}_{50}$ value $(25.51 \mathrm{ppm})$ after $48 \mathrm{~h}$ of exposure period. The essential oil showed the $\mathrm{LC}_{50}$ values of 119.52 (after $12 \mathrm{~h}$ ) and $67.53 \mathrm{ppm}$ (after $24 \mathrm{~h}$ ). Acetone and water showed no mortality after 24 and 48 h of exposure period. The larval mortality rate of the essential oil was entirely time and dose dependent. The results of the present study are comparable to the previous study made by Senthilkumar and Venkatesalu [9]. The essential oil of $P$. ambonicus showed larvicidal activity against $A n$. stephensi reared in the laboratory with the $\mathrm{LC}_{50}$ values of 33.54 (after $12 \mathrm{~h}$ ) and $28.37 \mathrm{ppm}$ (after $24 \mathrm{~h}$ ). The larval mortality ability of the essential oil may be accredited by the presence of Carvacrol in the essential oil [13]. The results of the present study are also similar to that of earlier investigations on larvicidal activity of essential oils. Pavela and others reported that the essential oils obtained from Thymus vulgaris, Satureja hortensis and Thymus satureioides showed the highest larvicidal effect $\left(\mathrm{LC}_{50} 33,36\right.$ and $44 \mu \mathrm{g} / \mathrm{ml}$, respectively) after $24 \mathrm{~h}$ of exposure [14]. Stem distilled essential oil from Zingiber officinalis was evaluated for larvicidal activity against the filarial mosquito, Culex quinquefasciatus. The late third instar larvae showed the $\mathrm{LC}_{50}$ value of $50.78 \mathrm{ppm}$ after $24 \mathrm{~h}$ of treatment [15]. It is apparent from the above mentioned results, the toxicity of essential oil against different mosquito species are not uncommon due to its chemical variations [16].

Malarial transmission is much more difficult to control in Africa as compared to most other places because of a complex ecological system, it can be prevented by effective vector control targeting larval habitats. Otherwise, endemic malaria cannot be eliminated from most parts of Sub-Saharan Africa [17]. In that way, the essential oil of Indian borage is a renowned natural source of larvicides for the control of the African malaria vector mosquito, An. gambiae.

\section{Conclusion}

The findings of this study have shown high mortality of An. gambiae s.l. third instar larvae caused by evaluated essential oils was dosage and time dependant. Further evaluations are ongoing for efficacy in semi field and subsequently small scale trials.

\section{Competing interests \\ Authors declare to have no competing interest in this work.}

\section{Authors' contribution}

EJK and W conceived and designed the study. AS, W and EJK carried out the data analysis and interpretation. EJK, W and AS wrote the manuscript and approved the final version for submission. All authors read and approved the final manuscript.

\section{Acknowledgements}

Authors are thankful to Wilberforce Onoka, Walter Mariga, Jersey Agalomba and Amos Wabwile for field larvae sampling and larvicides trials at Kenya Medical Research Institute, Kisumu Kenya.

\section{Author details}

${ }^{1}$ Division of Livestock and Human Diseases Vector Control, Tropical Pesticides Research Institute, Ngaramtoni, Off Nairobi Road, P.O. Box 3024, Arusha, Tanzania. ${ }^{2}$ Department of Botany, Annamalai University, Annamalai Nagar, Tamil Nadu 608 002, India.

Received: 13 October 2012 Accepted: 27 November 2012

Published: 3 December 2012

\section{References}

1. WHO: World Malaria Report 2011. Geneva, Switzerland: World Health Organization; 2011

2. Coetzee M: Distribution of the African malaria vectors of the Anopheles gambiae complex. AmJTrop Med Hyg 2004,

70:103-104.

3. Osse R, Aikpon R, Padonou G, Oussou O, Yadouleton A, Akogbeto M: Evaluation of the efficacy of bendiocarb in indoor residual spraying against pyrethroid resistant malaria vectors in Benin: results of the third campaign. Parasit Vectors 2012, 5:163.

4. WHO: World Malaria Report 2010. Geneva, Switzerland: World Health Organization; 2010.

5. Amer A, Mehlhorn H: Larvicidal effects of various essential oils against Aedes, Anopheles, and Culex larvae (Diptera, Culicidae). Parasitol Res 2006, 99:466-472.

6. Amer A, Mehlhorn $\mathrm{H}$ : Repellency effect of forty-one essential oils against Aedes, Anopheles, and Culex mosquitoes. Parasitol Res 2006, 99:478-490. 
7. Kweka EJ, Mosha FW, Lowassa A, Mahande AM, Mahande MJ, Massenga CP, Tenu F, Lyatuu EE, Mboya MA, Temu EA: Longitudinal evaluation of Ocimum and other plants effects on the feeding behavioral response of mosquitoes (Diptera: Culicidae) in the field in Tanzania. Parasit Vectors 2008, 1:42.

8. Kweka EJ, Munga S, Mahande AM, Msangi S, Mazigo HD, Adrias AQ, Matias JR: Protective efficacy of menthol propylene glycol carbonate compared to $\mathrm{N}$. $\mathrm{N}$-diethyl-methylbenzamide against mosquito bites in Northern Tanzania. Parasit Vectors 2012, 5:189.

9. Senthilkumar A, Venkatesalu V: Chemical composition and larvicidal activity of the essential oil of Plectranthus amboinicus (Lour.) Spreng against Anopheles stephensi: a malarial vector mosquito. Parasitol Res 2010, 107:1275-1278.

10. Scott JA, Brogdon WG, Collins FH: Identification of single specimens of the Anopheles gambiae complex by the polymerase chain reaction. AmJTrop Med Hyg 1993, 49:520-529.

11. World Health Organization: 2005. http://whqlibdoc.who.int/hq/2005/ WHO_CDS_WHOPES_GCDPP_2005.13.pdf. Guidelines for laboratory and field testing of mosquito larvicides.

12. Adams RP: Identification of essential oil compounds by gas chromatography and mass spectrometry. 4th edition. Corol stream: Allured Publishing Corporation; 2009.

13. Knio KM, Usta J, Dagher S, Zournajiam H, Kreydiyyeh S: Larvicidal activity of essential oil extracted from commonly used herbs in Lebanon against the seaside mosquito, Ochlerotatus caspius. Bioresour Technol 2008, 99:763-768.

14. Pavela R: Larvicidal property of essential oils against Culex quinquefasciatus Say (Diptera: Culicidae). Industr Crops and Prod 2009, 30:311-315.

15. Pushpanathan T, Jebanesan A, Govindarajan M: The essential oil of Zingiber officinalis Linn (Zingiberaceae) as a mosquito larvicidal and repellent agent against the filarial vector Culex quinquefasciatus Say (Diptera: Culicidae). Parasitol Res 2008, 102:1289-1291.

16. Sukumar K, Perich MJ, Boobar LR: Botanical derivatives in mosquito control: a review. J Am Mosa Control Assoc 1991, 7:210-237.

17. Killeen GF, Fillinger U, Kiche I, Gouagna LC, Knols BG: Eradication of Anopheles gambiae from Brazil: lessons for malaria control in Africa? Lancet Infect Dis 2002, 2:618-627.

doi:10.1186/1756-3305-5-277

Cite this article as: Kweka et al.: Toxicity of essential oil from Indian borage on the larvae of the African malaria vector mosquito, Anopheles gambiae. Parasites \& Vectors 2012 5:277.

\section{Submit your next manuscript to BioMed Central and take full advantage of:}

- Convenient online submission

- Thorough peer review

- No space constraints or color figure charges

- Immediate publication on acceptance

- Inclusion in PubMed, CAS, Scopus and Google Scholar

- Research which is freely available for redistribution 